\title{
A cross sectional study on willingness and acceptance of postpartum sterilization by mothers at a tertiary hospital
}

\author{
T. K. Shaanthy Gunasingh, T. S. Meena, R. Mothilal*
}

Department of Family Welfare, Government Kilpauk Medical College Hospital, Chennai, Tamil Nadu, India

Received: 01 April 2017

Revised: 01 May 2017

Accepted: 05 May 2017

\author{
*Correspondence: \\ Dr. R. Mothilal, \\ E-mail: mothilal15661@gmail.com
}

Copyright: (c) the author(s), publisher and licensee Medip Academy. This is an open-access article distributed under the terms of the Creative Commons Attribution Non-Commercial License, which permits unrestricted non-commercial use, distribution, and reproduction in any medium, provided the original work is properly cited.

\begin{abstract}
Background: India was the first country in the world to launch the Family Planning Programme in 1951. Despite this fact, India still lags behind in practicing contraception and limiting family size. Even though various measures for encouraging the usage of contraception have been taken up, the achievement in this field is not up to the expectation due to various social and cultural factors. The aim of our study is to estimate the prevalence of awareness, willingness and acceptance of postpartum sterilization among mothers who delivered with two and more children before discharge at a tertiary hospital.

Methods: It is a cross sectional study using the survey data on uncovered mothers who are discharged without accepting sterilization and mothers who underwent sterilization in a tertiary hospital.

Results: Total number of mothers with 2 and more living children was 231. All the mothers were aware of female sterilization method. Only $38.5 \%$ mothers underwent sterilization. $66.9 \%$ of mothers stated willingness for sterilization but not done among the uncovered mothers with 2 and more children. This disparity was due to various medical reasons (pediatric opinion $57.7 \%$, anesthetist opinion $0.7 \%$, not treated within 7 days of delivery $8.5 \%$ ).

Conclusions: In our study, the awareness of female sterilization in women was $100 \% .79 .6 \%$ of them were willing for sterilization. Women willing for sterilization were more in caesarean section $(45.4 \%)$ than in women who delivered vaginally $(34.2 \%)$.
\end{abstract}

Keywords: Acceptance, Postpartum, Willingness

\section{INTRODUCTION}

India is the second most populous country in the world and in the next few decades it will cross China if this exponential growth is maintained. ${ }^{1}$ All India Hospital Postpartum Programme is a maternity centered hospital based approach to Family Welfare Programme and aims to motivate women in reproductive age group (15-44 years) and their husbands for adoption of small family norms through education and motivation, particularly during prenatal, natal and post natal periods. ${ }^{2}$ The performance of the individual institution is assessed based on the annual work load of obstetrics (OB) cases taking into consideration its parity distribution. ${ }^{2}$ The acceptors have been grouped as direct and indirect acceptors. The direct acceptors are defined as all obstetrics cases attending hospital and accepting any family welfare method before discharge from the hospital. $^{2}$

The existing Direct acceptors for sterilization is $75 \%$ of OB cases with two or more living children and $50 \%$ of 
OB cases with one child for spacing methods. ${ }^{2}$ The National Family Health Survey -4 (2015-16) stated that the current rate of female sterilization is $36.0 \%$ in India. ${ }^{3}$ The National net replacement level of total fertility rate is 2.1 by $2010 .{ }^{4}$ As to attain this net replacement level of total fertility rate from the latest TFR 2.3 (SRS 2015) at least by 2020 and also to reduce the Higher Order of Birth (HOB) from $22.9 \%$ (SRS 2015), the Direct acceptors for sterilization should be more than $75 \%$ of Obstetrics (OB) cases with two and more living children. ${ }^{5}$

It is emphasized that immediate objective of the NPP 2000 is to address the unmet needs for contraception and the medium term objective is to bring the TFR to the replacement levels by $2010 .{ }^{4}$ In the National Social Demographic Goals for 2010, promoting vigorously small family norm to achieve replacement levels of TFR is the one among other goals. ${ }^{4}$ The aim of our study is to estimate the prevalence of awareness, willingness and acceptance of postpartum sterilization among mothers who delivered with two and more children before discharge at a tertiary hospital.

Objectives of present study were to assess the willingness for sterilization among mothers with 2 and more living children before discharge from Government Kilpauk Medical College Hospital, Chennai, for the reference period from $1^{\text {st }}$ December to $31^{\text {st }}$ December 2016 and to assess the independence of attributes of PPIUCD acceptance and willingness for sterilization among uncovered mothers with 2 and above living children before discharge from Government Kilpauk Medical College hospital, Chennai, for the reference period from $1^{\text {st }}$ December to $31^{\text {st }}$ December 2016.

\section{METHODS}

The survey data on uncovered mothers with 2 and above children without accepting tubal sterilization before discharge from the Government Kilpauk Medical College Hospital, Chennai-10 for the reference period from 1st December to 31st December 2016 was taken as secondary data in addition to the tubal sterilization acceptor among the mothers with 2 and more children for the above said period for this study. ${ }^{6,7}$ The statistical analysis $\mathrm{Z}$ test and chi-square test were used for this study. It is an analytical cross sectional study.

\section{Statistical analysis}

\section{Hypothesis I}

- H0: $=90 \%$ of mothers with 2 and more children willing for sterilization.

- H1: $<90 \%$ of mothers with 2 and more children willing for sterilization

Formula: $\mathrm{Z}=\mathrm{p}-\mathrm{P} 0 / \sqrt{ } \mathrm{PQ} / \mathrm{N}$
Where $\mathrm{p}$ is the proportion stated in the sample, PO is the proportion stated in the null hypothesis; $\mathrm{N}$ is the sample size and $\mathrm{Q}=1-\mathrm{P}$.

$\mathrm{p}=184 / 231=0.7965 ; \mathrm{P} 0=90 \%=0.90$

$Z=0.7965-0.90 / 0.0284=-5.24$

$P$ value is $<0.00001$

Since the calculated absolute $\mathrm{z}$ value $|5.24|$ is greater than 1.64 at (0.05) level of significance, we can reject the null hypothesis. Hence, the alternative hypothesis that less than $90 \%$ of mothers with 2 and more children, willing for sterilization is correct and statistically significant since $\mathrm{P}$ is $<0.05$. Therefore, $79.6 \%$ of mothers with 2 and more children showing willingness for sterilization in the sample is correct.

\section{Hypothesis II}

- Ho: The two attributes, PPIUCD and sterilization willingness are independent

- H1: PPIUCD and sterilization willingness are not independent.

Table 1: Willingness of sterilization and PPIUCD insertion among the uncovered mothers.

\begin{tabular}{|llll|}
$\begin{array}{llll}\text { Willingness for } \\
\text { sterilization }\end{array}$ & PPIUCD & Not & Total \\
Yes & 59 & 36 & 95 \\
inserted & \\
\hline No & 27 & 20 & 47 \\
\hline Total & 86 & 56 & 142 \\
\hline
\end{tabular}

Chi-square $=\mathrm{N} \times(\mathrm{ad}-\mathrm{bc}) \wedge 2 /(\mathrm{a}+\mathrm{b})(\mathrm{c}+\mathrm{d})(\mathrm{a}+\mathrm{c})(\mathrm{b}+\mathrm{d})=142 \times[$ $(59 \times 20)-(36 \times 27)]^{\wedge} 2 /(95 \times 47 \times 86 \times 56)=0.285$, d.f. $=(2-1)(2-$ 1) $=1 \times 1=1$

We cannot reject the null hypothesis, since the calculated chi-square $(0.285)$ is less than table value of chi-square (3.84) at 5\% 1.o.s, degrees of freedom $=1$ and hence the two attributes that mothers had PPIUCD insertion among the willing mothers for sterilization was the chance and they were independent among the uncovered mothers with 2 and above children.

\section{RESULTS}

The data generated in excel format for the survey on uncovered mothers with 2 and above children without accepting tubal sterilization before discharge from the Government Kilpauk medical college hospital, Chennai10 for the reference period from $1^{\text {st }}$ December to $31^{\text {st }}$ December 2016 and postpartum sterilization acceptor for the above said period were used. ${ }^{6,7}$

The Table 2 shows that $100 \%$ of awareness for tubal sterilization is prevailing among the multipara mothers 
who delivered vaginally and who underwent caesarean section. ${ }^{1,8-10}$

Table 2: Awareness of tubal sterilization.

\begin{tabular}{|llll|}
\hline $\begin{array}{l}\text { Mode of } \\
\text { delivery }\end{array}$ & Nos. & $\begin{array}{l}\text { Awareness of } \\
\text { sterilization }\end{array}$ & $\%$ \\
\hline $\begin{array}{l}\text { Vaginal } \\
\text { delivery }\end{array}$ & 118 & 118 & 100.0 \\
\hline LSCS & 113 & 113 & 100.0 \\
\hline Total & 231 & 231 & 100.0 \\
\hline
\end{tabular}

The Table 3 shows that $79.6 \%$ of women with two and more children were willing for tubal sterilization and $20.4 \%$ of them were not willing for sterilization. ${ }^{6-8}$

It was found that women willing for sterilization were more in caesarean section than in women who delivered vaginally and vice versa for not willing.
Table 3: Mode of delivery vs willingness for tubal sterilization.

\begin{tabular}{|llllll|}
\hline $\begin{array}{l}\text { Mode } \\
\text { of } \\
\text { delivery }\end{array}$ & \multicolumn{2}{l}{$\begin{array}{l}\text { Willingness for } \\
\text { sterilisation }\end{array}$} & \multicolumn{2}{l}{ Willing } & \multicolumn{2}{c|}{ Not willing } & \\
\hline $\begin{array}{l}\text { Vaginal } \\
\text { delivery }\end{array}$ & 79 & $34.2 \%$ & 39 & $16.9 \%$ & $118(51.1 \%)$ \\
\hline LSCS & 105 & $45.4 \%$ & 8 & $3.5 \%$ & $113(48.9 \%)$ \\
\hline Total & 184 & $79.6 \%$ & 47 & $20.4 \%$ & $231(100 \%)$ \\
\hline
\end{tabular}

The Table 4 shows that $38.5 \%$ mothers with two and more children underwent sterilization, $41.1 \%$ of them were willing but did not underwent sterilization and 20.4 $\%$ of them were not willing for sterilization. ${ }^{9}$

The Table 5 shows that $48.4 \%$ of mothers underwent sterilization and about $51.6 \%$ of mothers did not undergo sterilization among the willing mothers with 2 and above children due to various medical reasons.

Table 4: Mode of delivery vs willingness and performance of sterilization.

\begin{tabular}{|llllllll|}
\hline Mode of delivery & Willing and done & Willing and not done & Not willing & Total \\
\hline Vaginal delivery & 48 & $20.8 \%$ & 31 & $13.4 \%$ & 39 & $16.9 \%$ & $118(51.1 \%)$ \\
\hline Lscs & 41 & $17.7 \%$ & 64 & $27.7 \%$ & 8 & $03.5 \%$ & $113(48.9 \%)$ \\
\hline Total & 89 & $38.5 \%$ & 95 & $41.1 \%$ & 47 & $20.4 \%$ & $231(100 \%)$ \\
\hline
\end{tabular}

Table 5: Mode of delivery vs coverage of sterilization among willing mothers.

\begin{tabular}{|lllllll|}
\begin{tabular}{|l} 
Mode of \\
delivery
\end{tabular} & \multicolumn{4}{l}{$\begin{array}{l}\text { Coverage of sterilisation among } \\
\text { Willing mothers }\end{array}$} & Total \\
\hline $\begin{array}{l}\text { Covered } \\
\text { Vaginal } \\
\text { delivery }\end{array}$ & 48 & $26.1 \%$ & 31 & $16.8 \%$ & $\begin{array}{l}79 \\
\text { Not covered }\end{array}$ \\
\hline Lscs & 41 & $22.3 \%$ & 64 & $34.8 \%$ & $\begin{array}{l}105 \\
(57.1 \%)\end{array}$ \\
\hline Total & 89 & $48.4 \%$ & 95 & $51.6 \%$ & $\begin{array}{l}184 \\
(100 \%)\end{array}$ \\
\hline
\end{tabular}

The Table 6 reveals that $66.9 \%$ mothers were willing for sterilization but sterilization not done due to various medical reasons among the uncovered mothers (142) with 2 and above children for sterilisation.

The proportion of not doing sterilization immediately after delivery was 0.669 for medical reason (Pediatric opinion 0.577, Anesthetist opinion 0.007, not treated within 7 days of delivery .0845) and 0.331 for social causes among the uncovered mothers with 2 and above children.

It stands for medical and social reasons nearly at 2:1 ratio for not doing sterilization among the uncovered mothers with 2 and above children.
The Table 7 shows that uncovered mothers were not willing for sterilization immediately after delivery for various social causes. It reveals that $33.1 \%$ of mothers were not willing for sterilization after delivery. However, $16.9 \%$ of mothers have stated their willingness for interval TAT. $3.5 \%$ of mothers have shown their regret that baby was kept inside the new born care.

Further, it shows $3.5 \%$ and $2.1 \%$ of mother wants male and female baby respectively. ${ }^{9}$ The reason for $7 \%$ of mothers not undergoing sterilization was of husband not willing, selecting nearby hospital for sterilization, nobody to take care of the patient after sterilization and the health of the first baby being not good. ${ }^{9}$

In the study, 142 delivered mothers with 2 and above children without accepting sterilization discharged from the hospital was surveyed and the hospital statistics that 89 delivered mothers accepted tubal sterilization and 86 mothers with 2 and above children had PPIUCD insertion before discharge from the hospital during study period were taken and totally 231 delivered mothers with 2 and above children were analyzed wherein $100 \%$ of them were aware about tubal sterilization, $79.6 \%$ of them willing for tubal sterilization, $38.5 \%$ of them underwent tubal sterilization and $37.2 \%$ of mothers with 2 and above children had PPIUCD insertion were found. 
The proportion of willing mothers for tubal sterilization was $79.6 \%$ among the mothers with 2 and above children was correct in our study (z-test). It was found that the mothers had PPIUCD insertion among the unwilling mothers for sterilization was the chance.

Table 6: Reasons for not doing sterilization.

\begin{tabular}{|c|c|c|c|c|}
\hline $\begin{array}{l}\text { Reasons for not } \\
\text { doing sterilization }\end{array}$ & $\begin{array}{l}\text { Vaginal } \\
\text { delivery }\end{array}$ & LSCS & Total & $\%$ \\
\hline \multicolumn{5}{|l|}{ Paediatric opinion } \\
\hline Low birth weight & 2 & 3 & 5 & \\
\hline Neonatal jaundice & 1 & 0 & 1 & \\
\hline $\begin{array}{l}\text { Admission to NICU } \\
\text { other than LBW and } \\
\text { NNJ }\end{array}$ & 18 & 58 & 76 & \\
\hline Total & 21 & 61 & 82 & 57.7 \\
\hline \multicolumn{5}{|l|}{ Anaesthetist opinion } \\
\hline Heart disease & 0 & 0 & 0 & \\
\hline Respiratory infection & 1 & 0 & 1 & \\
\hline $\begin{array}{l}\text { Hypertensive disorders } \\
\text { and eclampsia }\end{array}$ & 0 & 0 & 0 & \\
\hline Total & 1 & 0 & 1 & 0.7 \\
\hline \multicolumn{5}{|c|}{ Not treated within 7 days of delivery } \\
\hline Respiratory infection & 3 & 0 & 3 & \\
\hline Anaemia & 5 & 3 & 8 & \\
\hline Others & 1 & 0 & 1 & \\
\hline Total & 9 & 3 & 12 & 8.5 \\
\hline $\begin{array}{l}\text { Total number of } \\
\text { women not undergoing } \\
\text { sterilization }\end{array}$ & 31 & 64 & 95 & 66.9 \\
\hline $\begin{array}{l}\text { Sterilization deferred } \\
\text { for medical reasons } \\
\text { but willing for } \\
\text { sterilization later }\end{array}$ & 31 & 63 & 94 & 66.2 \\
\hline
\end{tabular}

Table 6: Not willing for sterilization immediately after delivery.

\begin{tabular}{|lllll|}
\hline Reason & $\begin{array}{l}\text { Vaginal } \\
\text { delivery }\end{array}$ & LSCS & Total & $\%$ \\
\hline Husband & 3 & 1 & 4 & 2.8 \\
\hline $\begin{array}{l}\text { Selecting nearby } \\
\text { hospital }\end{array}$ & 2 & - & 2 & 1.4 \\
\hline Want of male baby & 5 & - & 5 & 3.5 \\
\hline Want of Female baby & 2 & 1 & 3 & 2.1 \\
\hline $\begin{array}{l}\text { Nobody to take care } \\
\text { of me }\end{array}$ & 2 & - & 2 & 1.4 \\
\hline $\begin{array}{l}\text { Baby was kept inside } \\
\text { the new born care }\end{array}$ & 5 & - & 5 & 3.5 \\
\hline $\begin{array}{l}\text { First baby health not } \\
\text { good }\end{array}$ & 2 & - & 2 & 1.4 \\
\hline Willing for TAT later & 18 & 6 & 24 & 16.9 \\
\hline Total & 39 & 8 & 47 & 33.1 \\
\hline
\end{tabular}

Analysing the mode of delivery with different cluster for sterilization, it was noted that willing for sterilization with LSCS was $45.4 \%$ and not willing for sterilization with LSCS was $3.5 \%$ but $17.7 \%$ only LSCS with sterilization.
Similarly, it was in vaginal delivery that willing for sterilization, not willing and vaginal delivery with sterilisation was $34.2 \%, 16.9$ and $20.8 \%$ respectively. This study also revealed that mother not willing for sterilization was lesser in caesarean section whereas it was more in vaginal delivery and it stood nearly at 1:5 ratio (Table 4).

\section{DISCUSSION}

\section{Awareness of tubal sterilization}

Patel A et al found in their study the knowledge of tubal ligation $100 \% .^{1}$ Vaithiyanathan A et al found in their study the awareness of tubectomy is $98 \% .{ }^{8}$ Sunita TH et al in the study that the awareness female sterilization is $100 \% .^{9}$ Geethalakshmi S, Chandrasekaran PA, Radha Rani $\mathrm{G}$ found awareness of tubectomy is $95.5 \% .^{10} \mathrm{In}$ present study the awareness of tubal sterilization was $100 \%$.

\section{Willing for sterilization}

Vaithiyanathan A et al found in their study that preferred method of female sterilization was $74.4 \% .^{8}$ In present study the willing for sterilization (79.6\%) stated was almost equal to it.

\section{Acceptance of female sterilization}

National Family Health Survey 4 stated that the current use of female sterilization in India was $36.0 \% .^{3}$ Sunita $\mathrm{TH}$, Rathnamal M Desai found in their study that female sterilization currently in use was $70.8 \% .{ }^{9}$ In present study the acceptance of female (tubal) sterilization immediately after delivery it was $38.5 \%$ and it was almost equal to NFHS -4 report. The common reasons behind it was the study conducted in different settings.

\section{Acceptance of PPIUCD}

The mothers with 2 and above children had PPIUCD insertion was $45.3 \%$ in the study conducted by Kanmani $\mathrm{K}$ et al. ${ }^{13}$ Similar findings was found in our study that it was $37.2 \%$.

\section{Mode of delivery and acceptance of sterilization}

In this study, those who undergo LSCS the acceptance rate was low because of deferral by pediatrician and willing for sterilization rate was high in LSCS because of there was no need for separate surgery. Similarly, the acceptance rate was slightly higher in vaginal deliveries and willing for sterilization rate was slightly lower in vaginal deliveries because of accepting temporary methods. In our study, the refusal was due to deferral by Pediatrician $57.7 \%, 9.2 \%$ of mother's illness not cured within 7 days of the delivery, $2.8 \%$ of mother's husband not willing for sterilization, $1.4 \%$ of mothers selecting nearby hospital for sterilization, $3.5 \%$ of mother want 
male baby, $2.1 \%$ of mother want female baby, $1.4 \%$ of mothers stated that nobody to take care of them, $1.4 \%$ of mothers regretted that the health of the first baby was not good, $16.9 \%$ of mothers do not want postpartum sterilization, $3.5 \%$ of mothers were apprehensive as the baby was admitted in newborn ward post-delivery. PPIUCD was inserted for those women if they were not willing for permanent method.

Similar findings was shown that LSCS with sterilisation rate was high because of no need for separate surgery and normal deliveries accepted temporary method; those with 2 children refused due to various factors like the children were of the same sex, the 2nd child of lower birth weight, need for extra stay in the hospital etc. and sometimes paediatrician fitness could not be obtained due to low birth weight and anaesthetist fitness could not be obtained due to medical disorders like heart disease, pre-eclapsia, anaemia, diabetes, which does not return to normal within the stipulated time of 7 days within delivery and PPIUCD was inserted for those women if they were not willing for permanent method were found in the study conducted by Kanmani K et al. ${ }^{14}$

\section{CONCLUSION}

Tubal sterilization is the most commonly performed permanent method of family planning all over the world. The current approach in family planning emphasizes on offering high quality contraceptive services among eligible clients on voluntary basis. In present study, $79.6 \%$ of mothers with 2 and more children were willing for sterilization but $38.5 \%$ only covered under tubal sterilization and $37.2 \%$ covered under PPIUCD before discharge at a tertiary hospital. $66.9 \%$ of uncovered mothers with 2 and more children willing for sterilization but not done sterilization before discharge from the hospital due to various medical reasons.

Present study shows that the coverage rate was still low in urban based areas where the need for motivation for the acceptors and the providers, the pediatricians have to be improved a lot. Not only timely correction of medical disorders so that the surgery can be performed within 7days of delivery also timely referral for interval TAT / MTP with TAT will help in reducing the high order births and its complications.

This study proved that the two attributes PPIUCD and mothers willing for sterilization among the uncovered mothers with 2 and more children, are independent. In our study, the result was proved that less than $90 \%$ of mothers with 2 and above children were willing for sterilization was scientifically correct and statistically significant.

\author{
Funding: No funding sources \\ Conflict of interest: None declared \\ Ethical approval: Not required
}

\section{REFERENCES}

1. Patel A, Pawani C, Patel R. Awareness and acceptance of contraceptive methods among post-partum patient. IJRCOG. 2016;5(I):206-9.

2. Directorate of Family Welfare, Chennai. In: PostPartum Programme Seminar Bulletin99-2000.

3. GOI. In: India Fact Sheet on National Family Health Survey NFHS- 4 (2015-16). Available from: http://rchiips.org/NFHS/pdf/NFHS4/India.pdf

4. GOI. In: The National Population Policy 2000. Available from: http://www.yourarticlelibrary.com/law/highlights-onnational-population-policy-2000-india/31384/

5. Registrar General of India, GOI. In: Statistical Report 2015, Sample Registration System. Available from: http://www.censusindia.gov.in/vital_statistics/SRS_Rep orts_2015.html.

6. Government Kilpauk Medical College Hospital, Chennai-10. In: The survey data on uncovered mothers with 2 and above children without accepting tubal sterilization before discharge from the for the reference period from 1st December to 31st December 2016.

7. Government Kilpauk Medical College Hospital, Chennai-10. In: Sterilization acceptor among the mothers with 2 and more children in vaginal and caesarean deliveries for the reference period from $1^{\text {st }}$ December to $31^{\text {st }}$ December 2016.

8. Vaidyanathan A, Priya KC, Seenivasan P, Malini G, Kaarthika T, Nathan D et al. A comparative study on the contraceptive methods preferred in rural and urban areas in Tamilnadu. Stanley Med J. 2014;1(2):4-8.

9. Sunita TH, Desai RM. Knowledge, attitude and practice of contraception among young women attending a tertiary care hospital in India. IJRCOG. 2013;(2):172-6.

10. Geethalakshmi S, Chandrasekaran PA, Radha Rani G. A study on factors influencing the choice permanent method of Family Planning. IOSR -JDMS: 2015;14:1622.

11. Dixit JV. Principles and Practice of Biostatistics. M/S. Banarisdas Bhanot (Publishers) 1167, Premnagar, Jabalpur. $3^{\text {rd }}$ edition; 2005.

12. United Nations, New York: 2006. 2007. In: World Population Prospects, Int. Highlights. Avialable from: http://www.un.org/esa/population/publications/wpp200 6/WPP2006_Highlights_rev.pdf

13. Kanmani K, Gokulakrishnan G, Rani PR., Acceptance of post placental intrauterine contraceptive device: recent increase in trend. IJRCOG. 2016;5(5):1341-4.

14. Kanmani K, Gokulakrishnan G, Rani PR. Study on permanent tubal sterilization in a semi- Urban based medical college hospital. IJRCOG. 2016;5(6):1736-8.

Cite this article as: Shaanthy Gunasingh TK, Meena TS, Mothilal R. A cross sectional study on willingness and acceptance of postpartum sterilization by mothers at a tertiary hospital. Int $\mathbf{J}$

Reprod Contracept Obstet Gynecol 2017;6:2517-21. 